Fischer's expression; but physiologists are still far from being sufficiently schooled in our science and progress has been chiefly due to men such as Emil Fischer, who have had sympathy with biological problems and been alive to the fact that it is desirable to walk before running. It is strange that few chemists have biological leanings-but the biological is still further removed than the chemical from the mathematical habit of mind.

The chief feature of progress in later years has been the ongrowth of the physical school. This has had both its advantages and its disadvantages -for whilst we have been led to widen our vision and increase our grip on the philosophy of our subject, we have lost in manipulative skill, as we have given inadequate attention to the development of method and technique. This probably is one of the chief causes of our comparative failure on the industrial side. Though based on analysis, chemistry is mainly a constructive, practical science: our success has been in proportion to the extent to which we have been able to confirm analytic by synthetic results. The man who does always gets ahead of the man who doesn't-of the man who merely seeks to explain; though the latter is often more useful than is supposed in controlling practice. Still it is because fingers and artistry come first in the practice of chemistry, that the chemist proper is not and cannot often be a mathematician. The superior value of the preparative side has been so brought home to us during the war, that it is to be hoped that full attention will now be given to its development.

Our ill-balanced bookish system of examinations is one of the main causes of the incomplete practical training chemists have received of late years; we have yet to teach the real value of books, that they are meant for constant reference; to force students to memorise them is the worst of policies : thoughtful, dextrous fingers and knowledge of materials are the chemist's chief needs.

Much progress has been made, on the physical side, in correlating properties with structure.
Also great attention has been paid to the problems of solutions: unfortunately the men who have dealt with this latter side of chemistry have not been working chemists -in fact, scarcely chemists at all-and the pseudo-mathematical treatment they have introduced has of ten savoured far too much of dogma. The result has been to introduce an unscientific, partial habit of mind into our subject. We are strangely behind in having no proper, accepted theory of chemical change in general. Our elementary text-books too are behind the times-full of half-truths and superficial when not inaccurate: there is no lack of detail but little philosophy and still less logic. Chemistry is the most fundamental of the sciences, the one by means of which it is alone possible to teach the principles and practice of scientific method in their entirety-and yet chemists are rarely trained to be masters of method.

To make chemistry a truly philosophical science, for the guidance of students, we need a man of giant mind, well versed in practice, who will survey and weigh the facts and give sympathetic consideration to all hypotheses, then summarise the situation in broad and simple terms which all can understand. Fitzgerald was a man of the type I have in mind.

Certainly the progress made during the fifty years is astaunding--the extent of our collective knowledge is extraordinary. But we must be on our guard-there are too many "bits of chemist" about: the most pretentious member of the species is of modern invention-the "research chemist." No chemist is a chemist who is not fully imbued with the spirit of inquiry. Not a little of the work that is now called research is of a trivial character; the majority are incapable of original effort and far more careful direction of advanced work is required. If care be not taken, "research" will become a word of reproach. The effort of the future must be to produce the whole chemist-the man who will know his subject and be ever careful and modest, both in word and deed, being possessed by scientific method.

\title{
THE DISCOVERY OF CHEMICAL ELEMENTS SINCE I869.
}

\section{By Prof. H. B. Dixon, F.R.S., and H. Stephen, M.Sc.}

A GLANCE at the history of the chemical elements reveals the fact that no fewer than fifty-three of them were recognised so early as 1818 , and since that time some thirty more have been discovered. The search for new elements between 1818 and 1869 represents an empirical programme without considerations of marked theoretical interest, and the investigations were directed more particularly to an examination of minerals. The chief results were the isolation of new metallic elements, and the work of the great master, Berzelius, stands out pre-eminently during this period, and his quantitative work surely paved the way for future investigations. NO. 26 ro, VOL. IO4]
The later period extending over the fast fifty years marks out a new era in the history of the chemical elements, inasmuch as it opened with the discovery of the periodicity of the elements in connection with their atomic weights. The elaboration of the system in its final form was due to Mendeléeff in 1869 , although Newlands had foreshadowed such a system in his law of octaves (1863).

Mendeléeff's system had a profound effect in bringing about radical changes in respect of the atomic weights of certain elements, notably beryllium, uranium, and indium; and in affording predictions of the existence and properties of new 
elements, which were confirmed with astonishing exactitude in the cases of scandium, gallium, and germanium.

Another factor which played an important rôle in the development of the chemistry of the elements in the early years of this period was the application of the spectroscope by Bunsen and Kirchhoff to chemical analysis, when, by a comparison of the bright lines in the spectra of the vapours of metallic elements with the dark lines in the solar spectrum, they showed that many terrestrial elements exist in the sun. During the last two decades the interest in spectroscopy has revived, and much of the valuable information which we now possess of the intra-atomic structures of the elements is due to the remarkable developments in the construction of diffraction gratings, and in particular the concave gratings of Rowland.

Notwithstanding the great possibilities for research opened up by Mendeléeff's periodic table, the latter remained only slightly modified until I893, when a period of rapid development and continual progress began. The later discoveries with regard to the chemical elements fall in a remarkable way into three distinct groups: the rare earths, the inactive gases, and the radioactive elements, and it is to be lamented that the pioneers in the two first-named groups have passed away.

Much of our knowledge of the rare earths is due to the late Sir William Crookes, who was the first to advance the conception of the metaelements i.e. elements which show great resemblance to each other, and have many physical and chemical properties in common, and, in consequence, are not easy to separate. Such in a few words sums up the chief characteristics of the rare earths, which have found so far only a temporary resting place in the periodic table. Apart from their purely acadomic interest and the high degree of accuracy attained in their separation, the rare earths have found important technical application as catalytic agents and in the manufacture of the modern incandescent mantle. Our knowledge of them, however, remains in many respects incomplete.

Of the second group, the inactive gases, we possess a more complete history of their chemistry, due in no small measure to the brilliant achievements of Lord Rayleigh and Sir William Ramsay, who were the first (1894) to characterise the inert gas argon in the atmosphere, and so confirmed the almost forgotten work of Cavendish more than a century before. The discovery of helium in cleveite by Ramsay followed shortly after that of argon; his attention had been directed by Miers to Hillebrand's discovery of nitrogen in the mineral uraninite-and gas-containing minerals seemed to be a possible storehouse of condensed argon. He sought for argon and found helium, the presence of which in the sun's atmosphere had been detected by Lockyer twenty-five years before.

The proof that helium was an inert monatomic gas like argon led to many speculations as to NO. $26 \mathrm{IO}$, VOL: IO4] the position of these new elements in the periodic system. Ramsay predicted the existence of another inert gas between, and forming a "triad" with, helium and argon, having an atomic weight between that of fluorine (19) and that of sodium (23), and he and his fellow-workers deliberately hunted for the missing element. They found it in the atmosphere, but besides the gas they sought-neon (20)-they also isolated the heavier elements krypton and xenon. All the inactive gases are colourless; they form no chemical compounds, and are monatomic. They have definite boiling points, give characteristic Geissler-tube spectra, and occupy a unique position in the periodic table-the neutral points in Crookes's descending figure of eight.

The last group of elements to be discovered include the remarkable and interesting series of radioactive elements, which originated in the discovery of radium by Mme. Curie in 1898 . The development of this field of research has produced a profound effect upon chemical theory and given us entirely new conceptions of the structure and nature of the atom, foremost among which is the nuclear atom proposed by Sir E. Rutherford, and recently modified by Prof. Bohr.

The chief interest of the radioactive elements centres round two elemerits of highest atomic weights, uranium and thorium, which are continually decomposing into a series of other elements at definite rates over which we have at present no control. These new elements in a similar way undergo spontaneous changes into still another series of elements. Accompanying these changes in both cases there is a high-speed emission of three distinct kinds of rays, now designated the $\alpha_{-}, \quad \beta-, \quad$ and $\gamma$-rays respectively. The first-mentioned have been identified as electrically charged atoms of helium, and it is now believed that all radio-elements are built up of lead and helium, a conclusion reached by Rutherford and others, and thus after the lapse of a century the hypothesis advanced by Prout (I 8 I5), concerning the existence of a primordial substance, makes a reappearance in modern guise.

The majority of the elements formed in the transformations associated with uranium and thorium (which are the progenitors of a long line of descendants) have not as yet been obtained in a pure condition, and are characterised at the present time solely in connection with radioactive properties. Two substances, radium and nitonthe gaseous emanation from radium-have been definitely described, and their atomic weights and positions in the periodic table fixed. Niton belongs also to the group of inactive gases; its existence is transitory, since the gas disappears after a few days, during the course of which radioactive disintegration takes place. Its atomic weight being 222 , four units less than radium, the difference is attributed to the loss of a helium atom from radium.

Based on a consideration of their researches, Rutherford and Soddy have formulated a theory of atomic disintegration (1902) in connection with 
which Soddy has recently introduced the term isotope, by which he defines very closely related elements which are chemically inseparable but have different atomic weights. The non-separability of isotopes by chemical methods has recently been confirmed by Richards and his co-workers, who found that the atomic weight of lead obtained from Australian carnotite (containing uraniumlead) was unaltered even after the nitrate into which the lead was converted had been subjected to more than a thousand fractional crystallisations. Furthermore, Richards has determined the atomic weight of uranium-lead, and the number found $(206.08)$ is less by as much as 0.25 per cent. than that of ordinary lead, which differs from it in other physical properties involving weight. It is possible that lead descended from thorium (208) and lead descended from uranium (206) have enough in common to be each called lead, but are varieties or isotopes of the same element, common lead $(207 \cdot 2)$ being a mixture of the two.

We may conclude, therefore, that in radioactive substances there is a continual transformation of one element into another of lower atomic weight, such transformation (apparently quite independent of temperature and external electrical conditions) being accompanied by the liberation of enormous amounts of energy, compared with which the magnitudes of energy of chemical reactions fade to insignificance. Has the earth passed through its element-building epoch? Instead of spinning "for ever down the ringing grooves of change," are we mounting backwards up the spiral as our larger empires of matter disintegrate into smaller and perhaps more stable states?

Just as the beginning of the last half-century was marked by the epoch-making discovery of the periodic system of the elements, so in effect is the close of it marked with another-namely, Moseley's discovery of the atomic numbers of the elements, the importance of which we have as yet scarcely realised.

The atomic number of an element as suggested by van der Broek defines the place-number occupied by the element in the periodic table, and at the same time is the number of electrons in the atom or nuclear charge of it. Moseley showed from a spectroscopic examination of the frequencies of characteristic X-rays emitted when $\mathrm{X}$-rays bombard anticathodes of various metals, that the square roots of the frequencies are proportional to the atomic numbers. The latter are known for all elements up to uranium--thus, hydrogen one, helium two, lithium three, and so on until finally uranium 92, and the anomalies which appear in Mendeléeff's table disappear, as in all cases the correct chemical order is maintained. The atomic numbers appear to be even more fundamental than the atomic weights.

\section{PHYSICAL CHEMISTRY-PAST AND PRESENT.}

\section{By Prof. J. C. Philip, F.R.S.}

$\mathrm{T}^{\mathrm{H}}$ $\mathrm{HE}$ cultivation of the border-lands between the various sciences, so actively prosecuted in the last few decades, has nowhere led to more notable results than on the frontiers of physics and chemistry. This particular field of investigation, covering phenomena in some measure common to both these sciences, has gradually taken shape, and has attracted crowds of workers, keen to apply the exact methods of physics to the wealth of problems and material presented by chemistry. With the passing of the vears physical chemistry has ultimately emerged as a definite branch of natural knowledge, full of intrinsic interest, but comprising also much that is of value for other sciences.

Fifty years ago the foundations of physical chemistry had to some extent been already laid. Faraday's experiments on electrolysis and the liquefaction of gases, Graham's observations on gaseous and liquid diffusion, and Hittorf's investigations of electrolytic migration had been put on record, although in some cases, notably the last-mentioned, the full significance of the work was not to be realised for many years to come. Avogadro's hypothesis and the kinetic theory were also before the scientific world, and the Brownian movement of minute particles No. 26 IO, VOL. IO 4$]$ suspended in water, destined ultimately to figure so prominently in the physical chemistry of recent years, had been not only recorded but, for the time, forgotten.

During the period in which NATURE first appeared, new methods of investigating chemical change, and new conceptions of chemistry as a quantitative science were being developed. The work of Harcourt and Esson, of Guldberg and Waage, on the action of mass as a factor in equilibrium and velocity, as well as Horstmann's application of thermodynamics to chemistry, inaugurated a new epoch, with which, in both directions, the name of van't Hoff was afterwards so brilliantly associated. It was van't Hoff who put the science of chemical dynamics on a secure experimental basis, and thus prepared the way for a rational study of catalysis, a particular development of vital significance for the growth of important chemical industries. It represents part of the contribution which physical chemistry has made to the advance of chemical knowledge from the purely descriptive to the rational and quantitative stage.

Appreciable progress towards the recognition of physical chemistry as a distinct branch of knowledge resulted, at a somewhat later date, 